\title{
COMPREENSÕES SOBRE O DISPOSITIVO: DA INFORMAÇÃO À VIA PARA PROFANAÇÃO ${ }^{1}$
}

\author{
COMPREHENSIONES SOBRE EL DISPOSITIVO: DE LA \\ INFORMACIÓN HACIA LA PROFANACIÓN
}

Jackson da Silva Medeiros *

\begin{abstract}
RESUMO
Introdução: A comunicação do conhecimento pode ser enxergada nas condições epistemológicas e institucionais da mediação do ciclo informacional, atuando como interveniente na construção social do conhecimento, controlada por regramentos explícitos ou implícitos que despertam ou que barram o fluxo do conhecimento. Objetivo: Explorar e refletir sobre dispositivos a partir da ideia que a verdade está colocada em ações e práticas contextualmente específicas, visando discutir e contribuir para uma sistematização das problemáticas "documento" e "informação", compreendendo e estrategizando relações de força e de poder. Metodologia: Leituras e interpretações da ideia de dispositivo, apresentada por Michel Foucault e posteriormente interpretada e trabalhada por outros autores, empreendendo sua construção no corpo conceitual da informação e do documento para acesso ao conhecimento científico. Resultados e Conclusões: Ainda parciais, os resultados apontam na direção de que dispositivos que se utilizam da informação e do documento operam no controle e nas estratégias de regulação do poder na comunicação da informação científica, já que este tipo de conhecimento é uma construção de uma verdade, sendo validados dentro de uma comunidade, necessitando do olhar sobre dispositivos que profanação ao sagrado.
\end{abstract}

Palavras-chave: Dispositivo. Documento. Comunicação científica. Informação científica.

\section{INTRODUÇÃO}

A informação e o documento devem ser encarados para além de seus suportes enquanto transmissores; devem ser vistos como implicadores de teorias, conceitos e metodologias relativos à sua constituição social como agentes instaurados e instauradores das relações do campo social. Devem ser

*Doutor em Comunicação e Informação - UFRGS. Professor doDepartamento de Ciências da Informação/UFRGS. E-mail: jackson.medeiros@ufrgs.br 
perquiridos como elementos que caracterizam a comunicação do conhecimento em estruturas de relações sociais, políticas, econômicas, culturais etc., extrapolando o objeto em si e fazendo com que sua atividade no mundo social possa ser compreendida.

Isso gera uma discussão que se inicia nas próprias definições de informação, inclusive, devido à complexidade de definir o objeto para estudo. $\mathrm{A}$ informação, como comunicação de conhecimento, pode ser enxergada nas condições epistemológicas e institucionais da mediação do ciclo informacional, atuando como interveniente na construção social do conhecimento, controlada por regramentos explícitos e/ou implícitos que despertam ou que barram o fluxo do conhecimento.

Por essa situação, este trabalho apresenta como proposta, valendo-nos de apropriações teóricas e conceituais a partir de aproximações epistemológicas oriundas de exploração da literatura, uma compreensão do dispositivo foucaultiano com vistas ao trabalho com o documento e suas relações enquanto agente social. A assimilação a partir das instituições do campo social, seja em nível macro ou micro, possibilita visualizar as relações dos dispositivos que são colocados como entes políticos, com ênfase em suas relações instauradoras e instauradas.

Este trabalho está enquadrado em uma perspectiva que parte de leituras e interpretações da ideia de dispositivo, apresentada por Michel Foucault e posteriormente interpretada e trabalhada por outros autores, com vistas a empreender sua construção no corpo conceitual da informação e do documento para acesso ao conhecimento científico. Para tal, partimos da ideia de que os dispositivos atuam como elementos das mais diversas ordens que visam estabilizar o arranjo das coisas, colocados em campos com delimitação espaço-temporal. Depois buscamos indicar o documento, principalmente o científico, e o acesso aberto enquanto dispositivos em um regime de verdade dentro desse campo. 


\section{DA POLÍTICA AO REGIME DE INFORMAÇÃO: APRESTO AO DISPOSITIVO}

O empreendimento aqui proposto é, em certa medida, uma tentativa de retorno, já que visa uma apresentação paralela ao que é comumente conceituado na literatura de Ciência da Informação como política e regime de informação. Como defende Sandra Braman (SILVA; GARCIA, 2016, p. 242), "política de informação tem um amplo domínio. É um termo guarda-chuva empregado para se referir a todas as leis e regulamentos que são aplicados a criação, processamento, fluxo e uso de informação". Política de informação é, genericamente, um termo que acaba sendo utilizado para indicar a relação do Estado com seus agentes a partir da informação. Pensado a partir da constituição comunicacional, mantém associação entre os níveis informacionais dos mais diversos agentes sociais, podendo pensar esses como actantes ${ }^{2}$ colocados em nível institucional.

Pierre Bourdieu (2011, p. 105) fala da relação do Estado com a informação e como este coordena suas ações: "O Estado concentra a informação, que analisa e redistribui. Realiza, sobretudo, uma unificação teórica". Tal realidade se dá pelas instituições a quem são atribuídas o caráter mantenedor do conhecimento reconhecido como válido (arquivos, bibliotecas etc.), por exemplo. Isso permite que o Estado fortaleça uma afirmação de sua identidade, sua cultura, sua política por meio de instrumentos de comunicação da informação que Ihe são característicos. O estímulo a determinado tipo de cultura, o que pode ser considerado memorável, passa a ser oficializado e oficial do Estado (SILVA; GARCIA, 2016).

Embora a conceituação de política de informação seja mantida em nível estatal, nosso esforço é a compreensão tanto macro quanto microcósmica. Tomando essas caracterizações, entendemos que, embora a literatura relate o termo/conceito, em geral, ligado às relações da informação com o Estado associada às políticas de ciência e tecnologia, política de informação é um termo que permite conceituar as relações em nível micro e macro-políticosocial, engendrando possibilidades de tratamento, ou melhor, de mediação, através de todo fluxo comunicacional e informacional. 
Pode, assim, ser genericamente caracterizada pelas atividades/processos de análise de seus modos de produção, registro, coleta, seleção, armazenamento, organização, validação, disseminação, avaliação e uso, mantendo ou não relação com o Estado, mas sempre, em algum nível, uma relação institucional. Pela complexidade, isso implica, como aponta González de Gómez (2002), em falta de estrutura institucional do Estado para implementação de políticas e sistemáticas em países em desenvolvimento, em virtude de desarticulações de interesses políticos e institucionais que incapacitam a informação a atuar como agente de transformações em estruturas muito voláteis, oriundas de instabilidades de conjunturas políticas.

Parece ter sido Bernd Frohmann, em 1995, o primeiro a explorar o conceito de regime de informação na área de Ciência da Informação. Isso oportunizou certo tipo de redução não redutora, permitindo que se enxergue além do conceito de política de informação como ações do Estado em relação à informação oficial, em um sentido de políticas de nações, mas possibilitando restringir à esferas, a campos menores, como laboratórios, práticas de comunicação, enfim, ambientes circunscritos, a possibilidade de descrever a tentativa de estabilização de jogos de interesse entre grupos, discursos e artefatos científicos e tecnológicos. A relevância dessa discussão também é compreendida por González de Gómez (2002) ao fazer referência ao trabalho de Jürgen Habermas: tentar compreender o todo, fazendo com que linguagens universais dominem os sistemas comunicacionais, é uma tarefa impraticável, já que os problemas microssociológicos que são colocados são culturalmente localizados, apreendidos de maneira a não ser possível formar uma ressonância na sociedade como um todo.

O contextual, localizado espaço-temporalmente, dita as regras institucionais que são instauradas pelo campo social. Com essa relação institucional, ligada ao campo, é possível abarcar sistemas de regulações e condições de existência que mantêm lógica interna e são implícita e explicitamente colocados, podendo "mascarar" o jogo a ser jogado. É parte do jogo a percepção do jogo em si, o conhecer o jogo, descobrindo-o e desbravando-o de forma a ser um player consciente do valor dos objetos que 
estão dispostos no campo e das estratégias de colocação de uma condição de existência.

No universo do regime de informação, a informação mantém relações com o poder, "alavancadas pela pressuposição de que a informação, como algo imerso nas tecnologias digitais e ubíquas, seria aquilo que nelas circula e as dinamiza." (GONZÁLEZ DE GÓMEZ, 2012, p. 44). Isso estaria associado à cadeia de produção de informação - indo da produção ao uso - , os elementos da infraestrutura de informação e os modos de informação.

Com ênfases nas dinâmicas antes que nas estruturas, o regime de informação permitiria associar a ancoragem espaçotemporal e cultural das ações de informação aos contextos regulatórios e tecnológicos que intervém e perpassam diferentes domínios de atividade, agências e organizações. (GONZÁLEZ DE GÓMEZ, 2012, p.56).

É possível que através do escrutínio proporcionado pelo regime de informação, este funcione como um descritor de agentes, percebendo suas insinuações explícitas e implícitas, legais, políticas, éticas, em questões de verdade e formas. O que entendemos é que um dispositivo é, com base em Michel Foucault, um gerenciador de seus valores. A verdade é dada a partir do que o campo coordena como sendo verdadeiro: metodologias, sistemáticas, informações, teorias, conceitos etc. A regulação de elementos é disposta de forma a criar uma cadeia de relações de força e poder capaz de coordenar esses elementos.

\section{SOBRE O DISPOSITIVO}

A problemática da verdade em Foucault, de fundamento nietzschiano, está constituída pelo devir, isto é, pelas transformações que se estabelecem a partir dos regimes de verdade instaurados. Estes possibilitam que os discursos sobre as coisas ajam de forma coercitiva e criem sistemas institucionais e de exclusão, podendo ser caracterizados a partir de dispositivos.

Nessa aproximação com o pensamento de Nietzsche e Foucault, não discutimos o que é verdade per se. Nosso entendimento, aliado a esses autores, é que a verdade é deste mundo, alcançável ao ser produzida através 
de dispositivos para um regime de verdade em que ela se torna justificável e, por esse viés, passível de análise.

\begin{abstract}
Cada sociedade tem seu regime de verdade, sua 'política geral' de verdade: isto é, os tipos de discurso que ela acolhe e faz funcionar como verdadeiros; os mecanismos e as instâncias que permitem distinguir os enunciados verdadeiros dos falsos, a maneira como se sanciona uns e outros; as técnicas e os procedimentos que são valorizados para a obtenção da verdade; o estatuto daqueles que têm o encargo de dizer o que funciona como verdadeiro. (FOUCAULT, 2012, p.52).
\end{abstract}

Ao pensarmos as constituições de regimes raciocinamos o contato de conjuntos de interesses que formam um tipo de estrutura abstrata que agencia indivíduos em situações concretas. Isso mantém um alto nível de reprodução dos campos sociais que colocam em permanência os postulados já consagrados, com o monopólio do capital específico, uma estruturação do poder simbólico dos dominantes, ratificando a (supra)(infra)estrutura necessária à circulação da informação, ou, novamente pensando em Foucault, de saber.

Parece-nos preciso quando Foucault (2004, p.299) fala da relação existente entre o agente e sua forma de agir; onde está a origem do agir, do pensar, do modo de existir que determina o pertencimento: "A maneira como as pessoas agem e reagem está ligada a uma maneira de pensar, e essa maneira de pensar está, naturalmente, ligada à tradição.". O dispositivo marcado por Foucault é, ao que entendemos, ao mesmo tempo e paradoxalmente, mais amplo, no sentido de possibilitar maior abrangência no leque de compreensões informacionais, e delimitador, permitindo especificar e configurando as margens, sempre fluidas, dos conceitos aqui trabalhados.

Com base nisso, podemos introduzir a noção de dispositivo que é, em Foucault, constituído a partir de sua etapa genealógica e se configura em estratégias que conformam as ideias e os corpos a partir de uma urgência que se instaura, tendo como sustentação as relações de saber e de poder. Assim se tem relações de força sobre as ações e regulações do que pode ser considerado como verdadeiro. 
Resumida por Foucault (2012, p.367), a noção de dispositivo pode ser enunciada, de forma genérica, como "estratégias de relações de força sustentando tipos de saber e sendo sustentadas por eles”. Em uma noção mais alongada, Foucault esclarece alguns pontos sobre o que entende ser um dispositivo:

[...] em primeiro lugar, um conjunto decididamente heterogêneo que engloba discursos, instituições, organizações arquitetônicas, decisões regulamentares, leis, medidas administrativas, enunciados científicos, proposições filosóficas, morais, filantrópicas. Em suma, o dito e o não dito são elementos do dispositivo. O dispositivo é a rede que se pode estabelecer entre esses elementos. Em segundo lugar, gostaria de demarcar a natureza da relação que pode existir entre esses elementos heterogêneos. Sendo assim, tal discurso pode aparecer como programa de uma instituição, ou, ao contrário, como elementos que permite justificar e mascarar uma prática que permanece muda; pode ainda funcionar como reinterpretação dessa prática, dando-lhe acesso a um novo campo de racionalidade. Em suma, entre estes elementos, discursivos ou não, existe um tipo de jogo, ou seja, mudanças de posição, modificações de funções, que também podem ser muito diferentes. Em terceiro lugar, entendo dispositivo como um tipo de formação que, em um determinado momento histórico, teve como função principal responder a uma urgência. O dispositivo tem, portanto, uma função estratégica dominante. (FOUCAULT, 2012, p. 364-365).

Foucault vai adiante, ensinando que o dispositivo mantém, caracteristicamente, um objetivo estratégico, tomando para si o que pode ser entendido como uma "sobredeterminação estratégica", ou seja, um processo de resposta a partir de um tipo de causa-efeito, constituindo-se de uma permanente rearticulação de um processo de atuar e de receber uma resposta. Processo que se coaduna em "preenchimentos estratégicos" com resultados não necessariamente esperados a partir de ações do dispositivo. Nessa acepção, o dispositivo não nasce do abstrato, mas é constituído a partir do fator espaço-temporal, isto é, contextualizado em um campo com suas matrizes objetivas e subjetivas, respondendo a uma situação estratégica.

O que temos, para Foucault, é o dispositivo como resposta a uma urgência, a uma indispensabilidade de pressupostos que, por necessidade 
daqueles que detêm o poder de instaurar o dispositivo, devem responder a uma contingência espaço-temporal, coordenando barreiras e fronteiras onde o "agir-além" decreta a perda de sentido. Essa é a função estratégica, o estabelecimento de funções que sejam capazes de neutralizar um rival, constituindo-se em ações das relações de poder.

Giorgio Agamben e Jeffrey Bussolini também se dedicaram a tratar o dispositivo foucaultiano. Agamben (2009, p.40), em extrapolação à conceituação proposta por Foucault, coloca-o em um amplo patamar de compreensão, abrangendo "[...] qualquer coisa que tenha de algum modo a capacidade de capturar, orientar, determinar, interceptar, modelar, controlar e assegurar os gestos, as condutas, as opiniões e os discursos dos seres viventes". Já Bussolini (2010) situa o dispositivo como uma ferramenta de análise e compreensão das relações de forças que estão em movimento e em embate em um campo social.

Concordando que própria resposta a uma ação é um tipo de exercício que acarreta em outra resposta, uma troca incessante entre agentes através de uma interação que arquiteta um processo transitório é baseada em causas espaciais e temporais. Pensar nessas características já é, por si só, buscar uma confluência entre elementos que, inclusive em sua heterogeneidade, coordenam-se e desordenam-se, "o que supõe que se trata no caso de uma certa manipulação das relações de força" (FOUCAULT, 2012, p.366-367), independentemente do tipo de ordem instaurada.

Outra questão relacionada ao dispositivo é que ele "está sempre inscrito em um jogo de poder, estando sempre, no entanto, ligado a uma ou a configurações de saber que dele nascem mas que igualmente o condicionam" (FOUCAULT, 2012, p.367). Aqui é importante relembrar que para Foucault os dispositivos têm gênese heterogênea, abarcando qualquer tipo de instituição, relação etc., podendo ser utilizados para se referir à dominação e certo tipo de subjetivação, possibilitando falar, por exemplo, em dispositivos de informação e dispositivos de sexualidade.

A inscrição de Foucault está na reapresentação de princípios de conduta, de comportamento do homem a partir de ligações que mantêm com a 
sociedade, sendo um tipo de vigilância que circunscreve o indivíduo. É esse sentido de imposição de vontades, de constrangimentos e de opressões que situam a relação percebida como dispositivo, derivando, como lembra Agamben (2009), da normatividade, das instituições, das palavras, das ordens, da liturgia que é interiorizada.

O dispositivo visto pelas relações de poder permite que este se mantenha ativo não por forças contrárias à vontade, mas na constituição do sujeito e na sua produção, enquanto saber e prazer, por discurso. Por esse modo de ver, o dispositivo não se encerra no objeto enquanto dispositivo, mas ele vetoriza e transporta uma série de elementos que permitem a análise do objeto (CHIGNOLA, 2016), com atuação em outros elementos da rede, criando, alterando, controlando, agindo sobre eles.

Se, como diz Agamben (2009), todo dispositivo mantém um desejo de felicidade ${ }^{3}$ do homem, há sentido na concretização de algo que é desejado. No entanto, a capacidade dos dispositivos de produzir sujeitos é a competência, ou falta dela, de se constituir como ser. Se o dispositivo atua sobre as ações, é a base de um reconhecimento do ser que deve responder a determinadas necessidades. O dispositivo tenta, forceja, aplica-se na docilização dos corpos, já que seu funcionamento depende de um processo de subjetivação.

Tavares e Loureiro (2017) afirmam que o dispositivo atua na transmutação dos seres em sujeitos, agenciando outros dispositivos, seus poderes, seus relacionamentos, suas conjunturas de existência, criando novos processos de subjetivação, originando uma aparência sombria da real concepção sobre o ser vivente. A criação do sujeito, na visão de Chignola (2014), é dada por relações em série, sendo o sujeito também um dispositivo que se conecta a outros dispositivos, agindo e fazendo agir. Nas palavras de Agamben (2009, p.38), "O termo dispositivo nomeia aquilo em que e por meio do qual se realiza uma pura atividade de governo sem nenhum fundamento no ser. Por isso os dispositivos devem sempre implicar um processo de subjetivação, isto é, devem produzir o sujeito.".

O dispositivo busca instaurar uma ordem contínua, ininterrupta, atuando em um processo de naturalização do instituído a partir da rede material e 
imaterial que carrega consigo e que se constitui em outros dispositivos. Mantenedor da ordem das coisas no regime instaurado, o dispositivo é um instrumento de estabilidade de situação em reprodução, sendo um continuum de novidades que se tornam o atual. Para Bussolini (2010), isso permite que atue com dinamismo contínuo, já que os elementos que o constituem podem fazer parte de mais de um dispositivo, bem como persistir às mudanças.

O dispositivo não se compreende a partir de categorias, de conceitos; no momento em que "Cada dispositivo representa o posicionamento mútuo de forças" (CHIGNOLA, 2012, p.10), sua formação é contextual, diferindo de um universal (como Agamben o posiciona) que teria uma constituição própria, constituindo-se por si só. Buscando um exemplo dentro da área de Biblioteconomia e Ciência da Informação, podemos pensar no processo de seleção quando ele age como dispositivo que determina novos dispositivos, ou seja, aqueles que foram selecionados e instauram outras relações de força, onde também estão situados outros dispositivos e elementos que constituem essa rede.

O sentido desperto do dispositivo é, assim, a seleção, o agrupamento e a disseminação de potenciais conjuntos informacionais capazes de estatuir latentes ações de informação tomadas como verdadeiras. Do mesmo modo que o dispositivo prisão cria uma série de marginalizados, como mostra Foucault, a seleção documental, por exemplo, cria aquilo que deve ou não deve ser reconhecido com conhecimento útil/válido.

As ações que são instauradas pelos dispositivos não podem ser consideradas ao acaso, por eventualidades, mas devem ser pensadas pela razão justificada do regime de verdade. Constituir uma nova ordem das coisas é criar um novo regime que esteja validado e reconhecido pelo regime atual. Há de se passar por uma alteração de sentidos daqueles que cercam o regime para que o novo seja o atual.

Essa forma de pensar pode ser vista no próprio Foucault na obra História da sexualidade l: a vontade de saber, quando o autor fala da virada e da reconfiguração entre os dispositivos de aliança e de sexualidade. Enquanto o primeiro estabelece um domínio de regras explícitas bem fixadas, como a 
herança de bens, o nome a ser dado, os parentescos, o segundo, através de uma mudança política na sociedade, estabelece uma sutileza nas relações; sutileza que não necessariamente conta com regras bem fixadas e explícitas.

Dessa forma, o esgotamento de um dispositivo, seja porque os interesses se deslocam ou se reajustam a partir de possibilidades políticas, econômicas, culturais etc., cria uma nova rede de dispositivos. Estes coordenam as ações de um campo, impondo novos elementos de poder que, espacial e temporalmente situados, permitem existência de novas ações e agentes que respondem às novas formas de poder.

Marteleto e Couzinet (2015, p.15) têm uma longa, embora genérica, explicação da forma como se pode abrir a caixa-preta em que um dispositivo pode se constituir:

Para estudar os dispositivos e mapear as zonas de mediações presentes em sua constituição é relevante considerar que o dispositivo info-comunicacional está associado aos quadros de ação dos sujeitos que o constituem, inseridos em determindas [sic] estruturas e redes de relações e limitações que circunscrevem os usos e as apropriações dos conhecimentos, das técnicas e das informações. Nesse âmbito, é relevante indagar a respeito dos sujeitos e como eles intervêm na construção ou na desconstrução dos dispositivos enquanto uma rede de elos sociais que ligam o produtor da informação, aquele que permite a circulação por meio de artefatos técnicos, o que intervem [sic] para facilitar a sua difusão, e aquele que se apropria da informação. (MARTELETO; COUZINET, 2015, p.15)

O interessante da proposição das autoras está, compreendemos assim, no fato de se tornar uma acepção que pode ser utilizada no âmbito da Ciência da Informação como aporte para as apropriações documentalistas de mediação de um fluxo informacional, representando a produção, registro, coleta, seleção, armazenamento, organização, validação, disseminação, avaliação e uso da informação com panorama para compreender seus efeitos na sociedade e nos fluxos científicos. Embora Tavares e Loureiro (2017, p.78) façam referência ao arquivo, a aproximação pode ser utilizada para as questões documentais como um todo, uma vez que decorrem da intencionalidade colocada sobre todo o fluxo documental: "[...] construção das memórias no interior do social. Por esse 
princípio de ação, encontram-se atrelados os aspectos da 'governamentalidade' nas sociedades de controle.".

A concepção de Wilke (2010) atua nesse sentido, em compreensão do dispositivo foucaultiano a partir do campo informacional - dispositivo informacional -, onde direciona seu entendimento a partir de três eixos: (a) conjunto de elementos não-discursivos e discursivos, incluindo instituições, organizações arquitetônicas, decisões regulamentares, leis, medidas administrativas, enunciados científicos, filosóficos, morais etc.; (b) jogos de força entre os elementos discursivos e não-discursivos em que não há posições e funções fixas relacionadas às mediações comunicacionais e informacionais; e (c) função estratégica, remetendo a uma forma peculiar de organização social, para geração, processamento e transmissão de informação como fontes de poder.

Como vimos, as ações de documentação não ocorrem ao acaso. $\mathrm{O}$ registro, a coleta, a seleção, a publicação etc., além de prática regida por uma tradição, é um dispositivo que está condicionado às regras explícitas e implícitas e age pelo governo dos sujeitos, fazendo com que seja "[...] antes de tudo, uma máquina que produz subjetivações e somente enquanto tal é também uma máquina de governo" (AGAMBEN, 2009, p.46). Assim, discutir o documento enquanto objeto relacional é cuidar do regime de verdade que o instaura e cria nele um dispositivo instaurador de outras verdades. Estas delimitam o que é informação e o que não é, por exemplo, o que é publicado e o que não é publicado, o que é selecionado como conhecimento válido, o que pode ou não ser dito.

\section{INFORMAÇÃO E DOCUMENTO COMO DISPOSITIVOS: PERCEPÇÕES E APROXIMAÇÕES}

No contexto de uma sociedade que se alicerça partir da informação e que esse objeto mantém interferências nas relações de mercado, capital, produção e trabalho, como já postulava Tauile em 1981, situar sua compreensão se faz necessário para que saibamos com o que pretendemos lidar. Isso permite que se empreenda o entendimento de uma ruptura onde 
produzir bens não compete mais a um mercado desenvolvido, mas entra em um rearranjo de estruturas do fluxo de informações, carregando, como estruturas, relações de poder.

Ao tratarmos a informação talvez estejamos lidando com um dos termos/conceitos mais polissêmicos que possam existir. Sua utilização e significação são dadas contextualmente e só assim há justificação do seu existir, não havendo critérios que determinem o que é ou não é informação (WERSIG; NEVELING, 1975). Segundo os autores, são seis tipos ou abordagens pelas quais informação pode ser caracterizada ${ }^{4}$, como: (i) estrutura; (ii) conhecimento; (iii) mensagem; (iv) significado; (v) efeito; e (vi) processo.

Buckland (1991) traça um correlativo à abordagem de Wersig e Neveling, mas aterrissa em outra direção. Para esse autor, informação apresenta três acepções: informação como processo; informação como conhecimento; informação como coisa. A primeira representa a ação de informar ou ser informado; o segundo sentido é baseado no primeiro, viável através da assimilação daquilo que foi comunicado (informado); a terceira acepção se constitui de materialidade que tem potencial informativo, isto é, aquilo que pode ser considerado como documento. A ideia de que objetos, de que coisas podem, em Buckland, ser consideradas documentos, está relacionada à materialidade da informação e sua possível disponibilidade para consulta e exame. No momento em que algo serve ou fornece evidência, pode ser considerado documento.

Essa articulação permite que pensemos algumas considerações sobre o documento enquanto subjetivação e agente subjetivador. $O$ documento passa a ser considerado, funcionalmente, como suporte à comunicação do conhecimento, isto é, como registro de algo situado no espaço e no tempo, passível de (re)ordenação e (re)exame. Ocorre que isso se dá de forma selecionada, tanto na sua criação (como instauração) como na sua disseminação (como instaurador de uma ordem). O que passa a existir, porque cumpre condições de existência, é aquilo que passa pela ordem da escolha, da 
seleção, sob o reger de forças que operam nesse sentido dentro de uma sociedade que o fabrica a partir de relações de poder.

Quando Frohmann (2009) revisa e atualiza a ideia sobre o que é um documento, partindo de Michael Buckland ${ }^{5}$, coloca o objeto para além de sua definição, além do que é e do que não, explorando que a formação discursiva da constituição do documento não é sua principal representação, deslocando sua ênfase no contexto de produção do documento. Isso já nos permite uma visualização de que a ideia de documento está sendo posta em caráter relacional, onde há de se considerar que a existência de um documento se coloca como importante a partir do momento em que agencia e é agenciado por outros elementos. Essa ideia também é exposta por Murguia (2014).

O documento, nesse sentido, passa a ser um registro da memória com dimensão simbólica da produção e da disseminação, e é instituído e institui determinadas relações. Ortega e Lara (2011, p.373), assumem que "Um documento se define como tal quando faz sentido para alguém em alguma circunstância. Esse aspecto pragmático revela o caráter social e simbólico da informação em face aos diferentes ambientes e situações concretas de uso.". Chegamos, então, à compreensão de que um documento só pode ser considerado como tal a partir do sentido que desperta, a partir de sua constituição simbólica como informação e, por consequência, pelo valor que instaura nas relações que vetoriza.

Indo ao encontro da ideia que os documentos dispõem de nãoocasionalidade na produção e uso, os sistemas formados por suas associações se agregam e se concatenam por força da relação de conhecimento circunscrita em informação que é instaurada, estabelecendo disposições que estão além do objeto, irrestritas aos sistemas documentais, mas que circulam num fluxo ininterrupto de relações e obrigações, implícitas e explícitas, para além da relação física. Como a sociedade contemporânea da informação se constitui na complexidade de suas instituições e agentes, possibilita - ou, na realidade, requer - que o tratamento a ser dado na manipulação desses dispositivos seja contextual, circunscrevendo campos que têm suas regras, seus valores instituídos e passíveis de investigação. 
Como Frohmann (2009) deixa claro, impulsionar o poder e a força do documento está mais ligado ao que ele pode fazer do que sua definição ou representação. Em uma acepção genérica, entendemos, o documento carrega a comunicação da informação. A rede começa a se desenhar no momento em que entendemos que "carregar" compreende algo que sai de um ponto e se desloca até outro ponto com determinado tipo de carga. Há, nessa simplória concepção, a visualização de um interesse em alguém que produz algo e alguém que ambiciona ter algo em sua posse. No caso da informação, o simbólico age de maneira peculiar, já que seu valor é baseado na necessidade e na potencialidade que a "carga" seja útil ao consumidor.

A própria "[...] recepção do documento é uma operação de construção ou reconstrução que mobiliza um conjunto de referências simbólicas, mas também circunstanciais e situacionais [...]" (LARA; ORTEGA, 2011, p. 384). Construção histórica, seletiva e adequada à relação de intencionalidade do ato de construção de um produto simbólico, fazendo necessário seu entendimento contextual em determinado jogo de verdades, jogo de símbolos. É por essa linha que Barry Smith (2012) caminha, colocando o documento como um agente social e institucional, constituindo-se do que chama de document acts, isto é, observando, para além dos registros, os atos humanos no uso dos documentos. Dessa forma, documentos podem ser considerados como um tipo de registro permanente que representa ou expressa um ou mais atos relevantes de forma deôntica ou institucional a partir de interações sociais.

$O$ documento se institui enquanto fundamento de verdade a partir da razão científica que regula sua fala e que o coloca como tal. A partir daí, como instaurador de sua própria fala, como ordenador de um (novo) discurso racional/científico, o documento ganha um status científico, um status de verdade, sendo, ao mesmo tempo, determinado e determinador em uma (nova) ordem das coisas. No momento que relacionamos o documento como um dispositivo, abre-se um escopo de relações congêneres de significação, isto é, as suas postulações enquanto dispositivo se ligam em uma rede de elementos que estão postas nele e fora dele de forma semelhante em atuação. Isso ativa e desativa outros dispositivos ao ligar e desligar regulações e implementações 
que são instauradas de forma canônica por uma institucionalização daquilo que o possibilita ser considerado um documento. Enquanto rede, o documento mantém e desloca vetores para outros dispositivos, para outros sistemas complexos que se ordenam e desordenam na constituição de outros dispositivos e, na relação com o mundo, estabelecem o sistema, ou melhor, o regime de verdade que é necessário à constituição do poder.

\section{CONSIDERAÇÕES}

Esta seção de considerações não está relacionada a algum tipo de "considerações finais", mas em um processo de construção que desponta e reverbera na comunicação da informação científica, já que este tipo de conhecimento é uma construção de uma verdade, testada por algum método que possibilita explicitar, compreender e falsear os caminhos percorridos. A validade é dada dentro de uma comunidade, a qual compartilha elementos de saber, a partir de canais que são reconhecidos como apropriados para disseminação do conhecimento que foi qualificado como tal com base em avaliação e chancela dos pares. Isso abre possibilidade para entender esse sistema de publicação como um dispositivo instaurado e instaurador de outros dispositivos, como a informação e o documento.

$\mathrm{Na}$ concepção de um poder relacional, como Foucault proclama, os dispositivos não são vetores de mão única. Se o poder está na relação, como postula o francês, os dispositivos são reversíveis no sentido em que apontam. Uma luta, uma batalha, uma resistência ao poder também é contrapartida por um dispositivo. Assim sendo, o dispositivo que regula, como o do sistema de publicações científicas tradicional, controlado por grandes editoras e sistemas complexos e caros de acesso à informação, aceita que outros dispositivos o profanem. Profanar, nesse sentido, dá-se por "devolver ao uso comum o que foi previamente separado na esfera do sagrado. No sentido mais amplo, desaplicar a lei e a soberania." (CHIGNOLA, 2014, p.17).

Esse é o caso das iniciativas de acesso aberto à informação científica. Há, por esse caminho, a possibilidade de se entender a sistemática em jogo de um complexo em que, a partir de um tempo e espaço definidos, haja uma luta 
de interesses, um conflito ambicionado e jogos de poder. Talvez essa seja a grande virada da profanação dos dispositivos: compreender a contenda do "novo" em relação ao "velho". Melhor colocado: do embate de proposições periféricas em relação ao tradicional; que possam fraturar o poder. Entendemos que as compreensões dessas questões permitem maior clareza de variáveis dos campos sociais e da interferência nas ações e nas necessidades e nas avaliações de informação. A variedade de dispositivos na manutenção de características institucionais deve ser escrutinada com vistas ao acesso à informação.

Uma vez que dispositivos extrapolam o indivíduo, possibilitam enxergar o campo social com perspectiva espaço-temporal, isto é, contextualizada através de sua perspectiva institucionalizante e institucionalizada em que as ligações formam o coletivo, ilustrando as vias que esses ocupam. Os dispositivos se constituem, na realidade, como as próprias regulações de critérios que devem ser vistos como verdadeiros.

As relações reguladoras dos regimes de verdade se mantêm em nível institucional, nas mais variadas esferas institucionais que, colocando-se como estruturas culturais e propositivas de atividades, agem nas ações de informação. Essas formas de possibilitar a existência do ser são discursivas e não discursivas em que existem apropriações e tentativas de justificar uma cultura de ordenação, de políticas, ou da falta disso, que estão pautadas por disposições econômicas, legais, políticas, culturais etc. Essa elementar exploração do pensar o documento enquanto dispositivo, com vistas ao sistema de publicação científica e ao acesso aberto, ecoa a partir dessa visão em que a verdade está colocada em ações e práticas de profanação contextualmente específicas.

\section{REFERÊNCIAS}

AGAMBEN, G. O que é um dispositivo? In: AGAMBEN, G. 0 que é o contemporâneo? E outros ensaios. Chapecó: Argos, 2009. 
BOURDIEU, P. Razões práticas: sobre a teoria da ação. 11. ed. Campinas: Papirus, 2011.

BUCKLAND, M. Information as thing. Journal of the American Society for Information Science, v. 42, n. 5, p. 351-360, 1991.

BUSSOLINI, J. What is a dispositive? Foucault Studies, n. 10, p. 85-107, nov. 2010.

CHIGNOLA, S. Sobre o dispositivo: Foucault, Agamben, Deleuze. Cadernos IHU ideias, ano 12, n. 214, v. 12, p. 3-18, 2014.

GONZÁLEZ DE GÓMEZ, M. N. Novos cenários políticos para a informação.

Ciência da Informação, v. 31, n. 1, p. 27-40, jan./abr. 2002.

GONZÁLEZ DE GÓMEZ, M. N. Regime de informação: construção de um conceito. Informação \& Sociedade: Estudos, v. 22, n. 3, p. 43-60, set./dez. 2012.

FOUCAULT, M. História da sexualidade I: a vontade de saber. Rio de Janeiro: Graal, 1988.

FOUCAULT, M. Microfísica do poder. 25. ed. Rio de Janeiro: Graal, 2012.

FOUCAULT, M. Verdade, poder e si mesmo. In: FOUCAULT, M. Ética, sexualidade e política. p. 294-300, 2004. (Ditos \& Escritos; V).

FROHMANN, B. Revisiting "what is a document?". Journal of Documentation, v. 65 , n. 2, p. 291-303, 2009.

FROHMANN, B. Taking information policy beyond information science: applying the actor network theory. ANNUAL CONFERENCE: CANADIAN

ASSOCIATION FOR INFORMATION, 23., 1995. Proceedings... Edmonton, Alberta: CAIS/ACSI, 1995.

LARA, M. L. G.; ORTEGA, C. D. Para uma abordagem contemporânea do documento na Ciência da Informação. International Society for Knowledge Organization, 20. Actas... Espanha: Universidade da Coruña, 2012. p. 371-387.

MURGUIA, E. I. Entrevista: Eduardo Ismael Murguia. InCID: Revista de Ciência da Informação e Documentação, v. 5, n. 2, p. 164-184, set. 2014/fev. 2015.

SILVA, E. M.; GARCIA, J. C. R. Política de Informação e Memória - Entrevista com Sandra Braman. Informação \& Sociedade: Estudos, v. 26, n. 3, p. 241245, set./dez. 2016. 
SMITH, B. Document acts. In: KONZELMANN-ZIV, A.; SCHMID, H. B. (Ed.). Institutions, Emotions, and Group Agents. Contributions to Social Ontology. Dordrecht: Springer, 2014, p. 19-31. (Philosophical Studies Series).

TAUILE, J. R. Uma introdução à economia política da informação. Ensaios FEE, Porto Alegre, v. 2, n. 2, p. 89-108, 1981.

TAVARES, D. W. S.; LOUREIRO, J. M. M. Dispositivos de informação: arquivos, memórias e informação. TransInformação, v. 29, n. 1, p. 73-80, jan./abr., 2017.

WERSIG, G.; NEVELING, U. The phenomena of interest to Information Science. Information Scientist, v. 9, n. 4, p. 127-140, dec. 1975.

WILKE, V. C. L. Informação, poder e estado: o dispositivo informacional e as políticas públicas de inclusão digital do governo brasileiro (2003-2008). In: ENCONTRO NACIONAL DE PESQUISA EM CIÊNCIA DA INFORMAÇÃO, 10., 2009, Anais... João Pessoa: ENANCIB/PPGCI/UFPB, 2009.

\title{
Titulo
}

Comprehensions on the dispositive: from information towards profanation

\begin{abstract}
Introduction: The knowledge communication can be seen in epistemological and institutional conditions of informational cycle mediation, acting as an intervener in the social construction of knowledge, controlled by explicit or implicit rules that awaken or bar the flow of knowledge. Objective: Explore and reflect on dispositive based on the idea that truth is based on actions and practices contextually specific, aiming to discuss and contribute to a systematization of "document" and "information", understanding and strategizing about power relations. Methodology: Readings and interpretations on dispositive, as presented by Michel Foucault and later interpreted and worked by other authors, undertaking its construction in the conceptual body of information and of document for scientific knowledge access. Results and Conclusions: Still partial, the results point in the direction that dispositives that use the information and the document operate in the control and in the strategies of regulation of the power in the communication of the scientific information. Knowing that scientific knowledge is a construction of a truth, being validated within a community, needing the look on dispositives that desecration the sacred.
\end{abstract}

Keywords: Dispositive. Document. Scholarly communication. Scientific information.

\section{Titulo}

Comprehensiones sobre el dispositivo: de la información hacia la profanación

Resumen

Introducción: La comunicación del conocimiento puede ser vista en las condiciones 
epistemológicas e institucionales de la mediación del ciclo informacional, actuando como interviniente en la construcción social del conocimiento, controlada por reglas explícitas o implícitas que despiertan o que barran el flujo del conocimiento. Objetivo: Explorar y reflexionar sobre dispositivos a partir de la idea de que la verdad está colocada en acciones y prácticas contextualmente específicas, buscando discutir y contribuir a una sistematización de las problemáticas "documento" e "información", comprendiendo y estratégizando relaciones de fuerza y poder. Metodología: Lecturas e interpretaciones de la idea de dispositivo, presentada por Michel Foucault y posteriormente interpretada y trabajada por otros autores, emprendiendo su construcción en el cuerpo conceptual de la información y del documento para acceso al conocimiento científico. Resultados y Conclusiones: Los resultados apuntan en la dirección de que dispositivos que se utilizan de la información y del documento operan en el control y en las estrategias de regulación del poder en la comunicación de la información científica, ya que este tipo de conocimiento es una construcción de una verdad, siendo validados dentro de una comunidad, necesitando la mirada sobre dispositivos que profanan al sagrado.

Palabras clave: Dispositivo. Documento. Comunicación académica. Información científica.

Recebido em: 19.06.2017

Enviado em: 11.12.2017

\footnotetext{
1 Trabalho desenvolvido sob os auspícios do CNPq

2 Utilizamos a expressão "actantes" de forma genérica, isto é, aqueles que executam ou sofrem algum tipo de ação, podendo ser seres humanos ou não humanos.

3 O conceito de felicidade, assim como diversos outros, é de difícil apreensão e objeto de estudo de diversas áreas. Não pretendemos fazer uma análise profunda dessa noção, mas para este trabalho entendemos por felicidade, de maneira ampla, a busca humana por algo que se situa no princípio do prazer.

${ }^{4}$ Não pretendemos analisar cada proposição realizada por Wersig e Neveling, uma vez que isso se constitui de resgate histórico e outras abordagens suprem essa explicação bem como adicionam elementos mais relevantes ao nosso trabalho. Para explicação sistemática, consultar WERSIG, G.; NEVELING, U. The phenomena of interest to Information Science. Information Scientist, v. 9, n. 4, p. 127-140, dec. 1975.

${ }^{5}$ Frohmann apresenta uma revisão do trabalho What is a document?, de Michael Buckland, publicado em 1997.
} 